\title{
Visible light mediated intermolecular [3 + 2] annulation of cyclopropylanilines with alkynes
}

Theresa H. Nguyen, Soumitra Maity and Nan Zheng ${ }^{\star}$

\section{Full Research Paper}

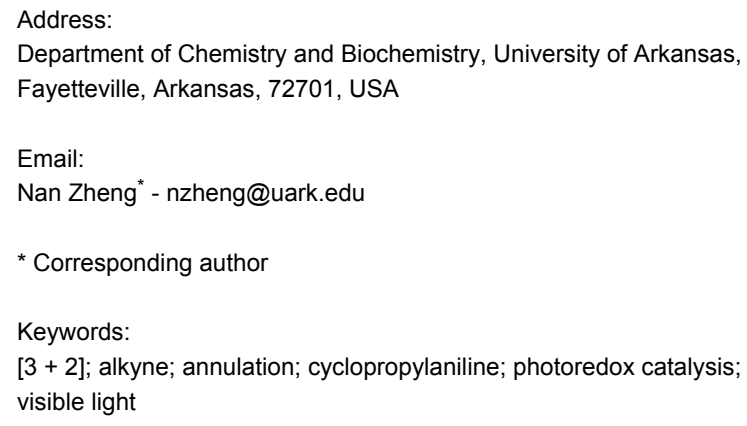

Beilstein J. Org. Chem. 2014, 10, 975-980. doi:10.3762/bjoc. 10.96

Received: 04 February 2014

Accepted: 04 April 2014

Published: 29 April 2014

This article is part of the Thematic Series "Organic synthesis using photoredox catalysis".

Guest Editor: A. G. Griesbeck

(C) 2014 Nguyen et al; licensee Beilstein-Institut.

License and terms: see end of document.

\begin{abstract}
Intermolecular [3 + 2] annulation of cyclopropylanilines with alkynes is realized using visible light photoredox catalysis, yielding a variety of cyclic allylic amines in fair to good yields. This method exhibits significant group tolerance particularly with heterocycles. It can also be used to prepare complex heterocycles such as fused indolines.
\end{abstract}

\section{Introduction}

Cyclopropanes have been used as a three-carbon synthon to prepare a diverse array of organic compounds [1-4]. The unusual reactivity, exhibited by cyclopropanes, is largely due to their inherent ring strain that makes cleavage of the $\mathrm{C}-\mathrm{C}$ bonds facile [5]. A number of methods have been developed to regioselectively cleave cyclopropanes, generating synthetically useful intermediates that can be further manipulated [1-5]. For one subclass of cyclopropanes, cyclopropylamines, the requisite ring opening is often accomplished by one-electron oxidation of the parent amine. This oxidation step can be realized enzymatically [6-8], chemically [9-14], electrochemically $[15,16]$, and photochemically [17-20]. Recently, visible light photoredox catalysis has emerged as a powerful method to manipulate the redox chemistry of organic compounds [21-26]. Amines have been used as an electron donor to reduce the excited state of photocatalysts, while they are oxidized to amine radical cations. Our group and others have taken advantage of this facile redox process and developed a number of synthetic methods that harness the synthetic potential of amine radical cations $[21,27,28]$. One of the reported methods from our group involves [3+2] annulation of cyclopropylanilines with alkenes [29]. We were intrigued by the possibility of extending this annulation method to include alkynes. The immediate benefits of using alkynes include eliminating the diastereoselectivity issue observed in the annulation of monocyclic cyclopropylanilines with alkenes and introducing an alkene functional 
group into the annulation product. Furthermore, the synthesis of cyclic allylic amines is non-trivial in general [30]. Herein, we report intermolecular [3+2] annulation of monocyclic cyclopropylanilines with alkynes under visible light photoredox conditions.

\section{Results and Discussion}

Biphenylcyclopropylamine $\mathbf{1}$ and phenylacetylene (2) were chosen as the standard substrates to optimize the catalyst system for the $[3+2]$ annulation with alkynes (Table 1). Similar to the annulation with alkenes [29], several reactivity patterns were observed. $\mathrm{CH}_{3} \mathrm{NO}_{2}$ was far superior to DMF and $\mathrm{CH}_{3} \mathrm{CN}$ as the solvent (Table 1; entries 1-3). $\mathrm{Ru}(\mathrm{bpz})_{3}\left(\mathrm{PF}_{6}\right)_{2}$ was a more effective photocatalyst than $\mathrm{Ru}(\mathrm{bpy})_{3}\left(\mathrm{PF}_{6}\right)_{2}$ (Table 1, entry 4). Air was detrimental to the annulation reaction (Table 1, entry 5). However, we noticed the annulation with alkynes was slower than with alkenes, previously reported by our group [29]. To compensate for lower reactivity of alkynes, we investigated commercially available light resources that were stronger than $13 \mathrm{~W}$ compact fluorescent lamps (CFLs). $13 \mathrm{~W}$ CFLs were used as the light source to mediate the annulation with alkenes
[29]. White $18 \mathrm{~W}$ LEDs were found to be more effective for the annulation with alkynes, resulting in a higher yield (Table 1, entry 6). Control studies showed that both the photocatalyst and light were required, though some background reaction was observed (Table 1, entries 7 and 8).

To determine the scope of this annulation process, a range of cyclopropylanilines with various electronic and steric characteristics were prepared and then subjected to the optimized catalyst system. The results of the scope studies are summarized in Figure 1. Both electron-donating (OMe, 7, and OTBS, 8) and electron-withdrawing $\left(\mathrm{CF}_{3}, \mathbf{9}, \mathbf{1 4}, \mathbf{1 8}\right.$, and $\left.\mathrm{CN}, \mathbf{1 0}, \mathbf{1 3}\right)$ substituents were well tolerated, and the annulation products were generally obtained in modest to good yields. The annulation process also tolerated steric hindrance. Hindered cyclopropylanilines, such as those possessing an ortho-isopropyl group, were satisfactorily converted to the annulation products (6 and 12). With respect to the other annulation partner, terminal alkynes substituted with an electron-withdrawing group were typically required for the annulation process. Alkylsubstituted terminal alkynes and internal alkynes were not reac-

Table 1: Catalyst screening<smiles>O=[W]OCCCC#Cc1ccccc1</smiles>

2<smiles>C1=C(c2ccccc2)C(Nc2ccccc2-c2ccccc2)CC1</smiles>

3

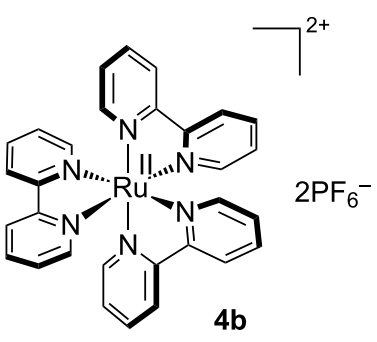

\begin{tabular}{|c|c|c|c|c|}
\hline Entrya & Catalyst & Light & Solvent & GC yield of $3[\%]^{b}$ \\
\hline 1 & $4 a$ & 18 W LED & $\mathrm{CH}_{3} \mathrm{NO}_{2}$ & $82(80)^{c}$ \\
\hline 2 & $4 a$ & 18 W LED & DMF & 20 \\
\hline 3 & $4 a$ & 18 W LED & $\mathrm{CH}_{3} \mathrm{CN}$ & 36 \\
\hline 4 & $4 b$ & 18 W LED & $\mathrm{CH}_{3} \mathrm{NO}_{2}$ & 55 \\
\hline $5^{d}$ & $4 a$ & 18 W LED & $\mathrm{CH}_{3} \mathrm{NO}_{2}$ & 41 \\
\hline 6 & $4 a$ & 13 W CFL & $\mathrm{CH}_{3} \mathrm{NO}_{2}$ & 68 \\
\hline 7 & none & 18 W LED & $\mathrm{CH}_{3} \mathrm{NO}_{2}$ & 6 \\
\hline 8 & $4 a$ & none & $\mathrm{CH}_{3} \mathrm{NO}_{2}$ & 3 \\
\hline
\end{tabular}

aConditions: $1(0.2 \mathrm{mmol}), 2(1 \mathrm{mmol})$, solvent $(2 \mathrm{~mL})$, degassed, irradiation at rt for $8 \mathrm{~h}$. ${ }^{\mathrm{b}}$ Dodecane was used as an internal standard. ${ }^{\mathrm{C}}$ Isolated yield by silica gel chromatography. ${ }^{\mathrm{d}}$ The reaction was conducted in the presence of air. 


$$
\triangle_{\mathrm{H}^{-}} \mathrm{Ar}+\mathrm{R}=\frac{\mathbf{4 a}(2 \mathrm{~mol} \%)}{\begin{array}{l}
\mathrm{CH}_{3} \mathrm{NO}_{2}, 18 \mathrm{~W} \mathrm{LED} \\
\text { degassed, 8-24 h }
\end{array}}
$$<smiles>Cc1cc(C)cc(NC2CCC=C2c2ccccc2)c1</smiles>

5, $62 \%$<smiles>FC(F)(F)c1ccc(NC2CCC=C2c2ccccc2)cc1</smiles>

9, 59\%<smiles>COC(=O)C1=CCCC1Nc1ccc(C#N)cc1</smiles><smiles>COC(=O)C1=CCCC1Nc1ccc(C(F)(F)F)cc1</smiles>

$13,72 \%$<smiles>CC(C)c1ccccc1NC1CCC=C1c1ccccc1</smiles>

6, $43 \%$<smiles>COc1ccc(NC2CCC=C2c2ccccc2)cc1</smiles><smiles>CC(C)(C)Oc1ccc(NC2CCC=C2c2ccccc2)cc1</smiles>

7, $45 \%$<smiles>COC(=O)C1=CCCC1Nc1ccccc1-c1ccccc1</smiles>

$11,68 \%$<smiles>C1=C(c2cccs2)C(Nc2ccccc2-c2ccccc2)CC1</smiles>

$15,45 \%$<smiles>COC(=O)C1=CCCC1Nc1ccccc1C(C)C</smiles>

$12,65 \%$
$14,70 \%$<smiles>C1=C(c2cccnc2)C(Nc2ccccc2-c2ccccc2)CC1</smiles>

$17,64 \%$<smiles>FC(F)(F)c1ccc(NC2CCC=C2c2ccccn2)cc1</smiles>

18, $42 \%$

Figure 1: Substrate scope.

tive under the optimized conditions. This reactivity trend towards alkynes is consistent with that exhibited in intermolecular addition of nucleophilic carbon-based radicals to alkynes [31-33]. In addition to phenylacetylene, acetylenic methyl ester is a viable annulation partner, leading to annulation products 11-14 in good yields. Heterocycles are frequently used in organic electronic materials [34] and pharmaceuticals [35,36]. Therefore, the ability to incorporate them is usually considered a benchmark for developing new synthetic methods. This method has certainly passed this test as two pairs of heterocycle-containing alkynes underwent the $[3+2]$ annulation with cyclopropylanilines uneventfully (15-18). The alkyne moiety at the $\mathrm{C} 2$ or $\mathrm{C} 3$ position of thiophene or pyridine showed similar reactivity towards the annulation.

Fused indolines are common structural motifs that appear in a number of biologically active alkaloids and pharmaceuticals $[37,38]$. The $[3+2]$ annulation of monocyclic cyclopropylanilines with alkynes provides a fast entry to this motif (Scheme 1). Starting from commercially available 1-bromo-2iodobenzene (19) and cycloproylamine, 2-bromo- $\mathrm{N}$-cyclopropylaniline (20) was prepared in $75 \%$ yield via the Buch- 


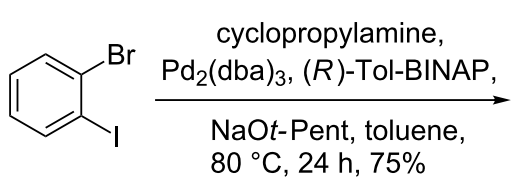

19

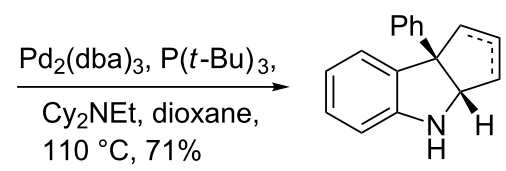

22<smiles>Brc1ccccc1NC1CC1</smiles>

20

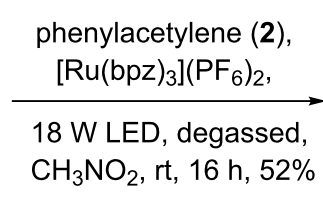

18 W LED, degassed,<smiles>P[C@@]12CCC[C@H]1Nc1ccccc12</smiles>

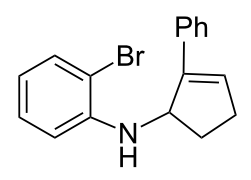

21

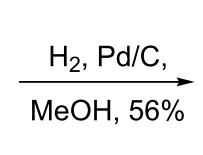

$\frac{\mathrm{H}_{2}, \mathrm{Pd} / \mathrm{C} \text {, }}{\mathrm{MeOH}, 56 \%}$

23

Scheme 1: Synthesis of a fused indoline

wald-Hartwig amination [39,40]. The $[3+2]$ annulation of 2-bromo- $N$-cyclopropylaniline (20) and phenylacetylene (2) was performed using the optimized catalyst system to provide cyclic allylic amine $\mathbf{2 1}$ in 52\% yield. The fused indoline motif was formed via an intramolecular Heck reaction under Fu's conditions [41] to provide a mixture of two olefinic regioisomers 22, which were converted to saturated fused indoline $\mathbf{2 3}$ under standard catalytic hydrogenation conditions in a combined yield of $40 \%$ from 21 .

Mechanistically, the annulation with alkynes probably proceeds through a pathway similar to the one we proposed for the annulation with alkenes (Scheme 2) [29]. The photoexcited $\mathrm{Ru}(\mathrm{bpz})_{3}{ }^{2+}$ oxidizes cyclopropylaniline 24 to the corresponding amine radical cation $\mathbf{2 5}$, which triggers the cyclopropyl ring opening to generate distonic radical cation $\mathbf{2 6}$. The primary carbon radical of $\mathbf{2 6}$ adds to the terminal carbon of alkyne $\mathbf{2 7}$ to afford vinyl radical 28. Intramolecular addition of the vinyl radical to the iminium ion of distonic radical cation $\mathbf{2 8}$ closes the five membered ring and furnishes amine radical cation 29. Finally, $\mathrm{Ru}(\mathrm{bpz})_{3}{ }^{1+}$ reduces amine radical cation 29 to the annulation product 30 while regenerating $\mathrm{Ru}(\mathrm{bpz})_{3}{ }^{2+}$. The proposed mechanism accounts for lower reactivity of alkynes towards intermolecular addition of nucleophilic carboncentered radicals as well as their regiochemistry in the annulation [31-33]. Addition of radicals to alkynes generally occurs at the less hindered carbon, i.e., the terminal carbon.

\section{Conclusion}

In summary, we have successfully expanded the $[3+2]$ annulation of cyclopropylanilines to include alkynes. This annulation process with alkynes has addressed some limitations existing in the annulation with alkenes. Moreover, the annulation products from alkynes are highly useful synthetic intermediates. Their utility is demonstrated by a four-step synthesis of fused indolines in which the $[3+2]$ annulation with alkynes is used to set

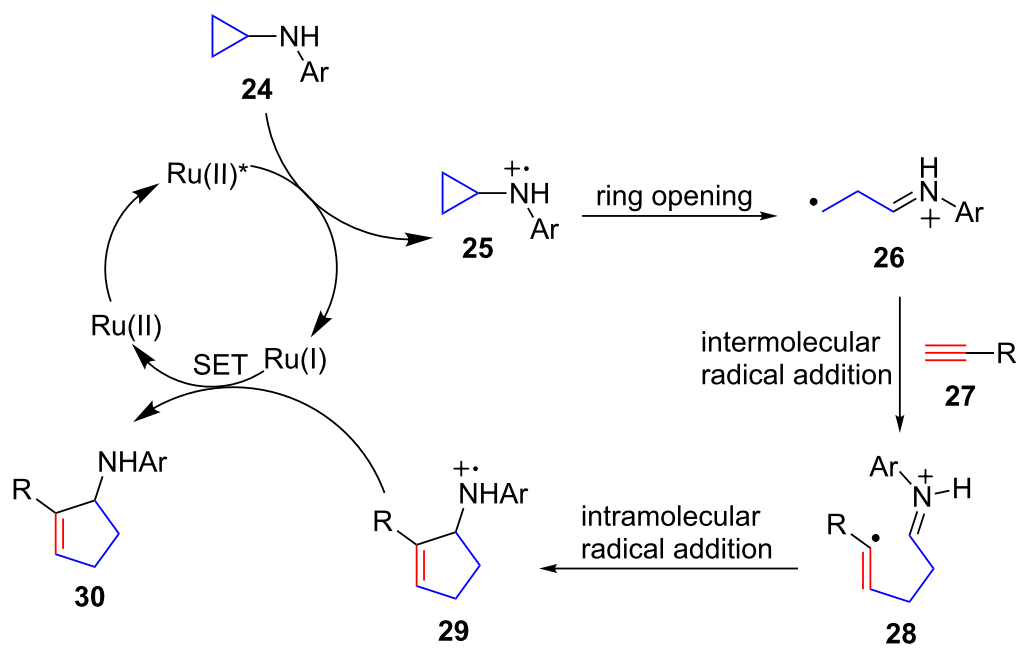


up the backbone of indolines. Continued studies in our group will focus on further expanding the scope of the $[3+2]$ annulation to include substituted anilines and other types of $\pi$-bonds.

\section{Experimental}

General procedure for the $[3+2]$ annulation of cyclopropylanilines with alkynes: an oven-dried test tube $(16 \times 125 \mathrm{~mm})$ equipped with a stir bar was charged with $\left[\mathrm{Ru}(\mathrm{bpz})_{3}\right]\left(\mathrm{PF}_{6}\right)_{2} \cdot 2 \mathrm{H}_{2} \mathrm{O}$ (2 mol \%), cyclopropylaniline (0.2 mmol), alkyne (1.0 mmol), and dry $\mathrm{CH}_{3} \mathrm{NO}_{2}(2 \mathrm{~mL})$. The test tube was sealed with a Teflon screw cap. The reaction mixture was degassed by Freeze-Pump-Thaw cycles and then irradiated at room temperature with one white LED (18 watts) positioned $8 \mathrm{~cm}$ from the test tube. After the reaction was complete as monitored by TLC, the mixture was diluted with diethyl ether and filtered through a short pad of silica gel. The filtrate was concentrated in vacuum and purified by silica gel flash chromatography to afford the desired allylic amine.

\section{Supporting Information}

\section{Supporting Information File 1}

Experimental procedures, compound characterization, and NMR spectra.

[http://www.beilstein-journals.org/bjoc/content/ supplementary/1860-5397-10-96-S1.pdf]

\section{Acknowledgements}

This publication was supported by the University of Arkansas, Arkansas Bioscience Institute, Grant Number P30 GM103450 from the National Institute of General Medical Sciences of the National Institutes of Health (NIH), NSF Career Award under Award Number CHE-1255539. We thank Jiang Wang and Mack D. Clements for early experimental assistance.

\section{References}

1. Reissig, H.-U.; Zimmer, R. Chem. Rev. 2003, 103, 1151-1196. doi:10.1021/cr010016n

2. Yu, M.; Pagenkopf, B. L. Tetrahedron 2005, 61, 321-347. doi:10.1016/j.tet.2004.10.077

3. Carson, C. A.; Kerr, M. A. Chem. Soc. Rev. 2009, 38, 3051-3060. doi:10.1039/b901245c

4. Tang, P.; Qin, Y. Synthesis 2012, 2969-2984. doi:10.1055/s-0032-1317011

5. Wong, H. N. C.; Hon, M.-Y.; Tse, C.-W.; Yip, Y.-C.; Tanko, J.; Hudlicky, T. Chem. Rev. 1989, 89, 165-198. doi:10.1021/cr00091a005

6. Zhong, B.; Silverman, R. B. J. Am. Chem. Soc. 1997, 119, 6690-6691. doi:10.1021/ja9711369

7. Shaffer, C. L.; Morton, M. D.; Hanzlik, R. P. J. Am. Chem. Soc. 2001, 123, 349-350. doi:10.1021/ja003048I

8. Wessjohann, L. A.; Brandt, W.; Thiemann, T. Chem. Rev. 2003, 103, 1625-1648. doi:10.1021/cr0100188
9. Hiyama, T.; Koide, H.; Nozaki, H. Tetrahedron Lett. 1973, 14, 2143-2144. doi:10.1016/S0040-4039(01)87579-1

10. Itoh, T.; Kaneda, K.; Teranishi, S. Tetrahedron Lett. 1975, 16 , 2801-2804. doi:10.1016/S0040-4039(00)75244-0

11. Takemoto, Y.; Yamagata, S.; Furuse, S.; Hayase, H.; Echigo, T.; Iwata, C. Chem. Commun. 1998, 651-652. doi:10.1039/A800125A

12. Loeppky, R. N.; Elomari, S. J. Org. Chem. 2000, 65, 96-103. doi:10.1021/jo991104z

13. Wimalasena, K.; Wickman, H. B.; Mahindaratne, M. P. D. Eur. J. Org. Chem. 2001, 3811-3817. doi:10.1002/1099-0690(200110)2001:20<3811::AID-EJOC3811>3.0.C O;2-6

14. Lee, H. B.; Sung, M. J.; Blackstock, S. C.; Cha, J. K. J. Am. Chem. Soc. 2001, 123, 11322-11324. doi:10.1021/ja017043f

15. Li, X.; Grimm, M. L.; Igarashi, K.; Castagnoli, N., Jr.; Tanko, J. M. Chem. Commun. 2007, 2648-2650. doi:10.1039/B702157G

16. Madelaine, C.; Six, Y.; Buriez, O. Angew. Chem., Int. Ed. 2007, 46, 8046-8049. doi:10.1002/anie.200702903

17. Rynbrandt, R. H.; Dutton, F. E. J. Org. Chem. 1975, 40, 3079-3081. doi:10.1021/jo00909a014

18. Lee, J.; Sun, U. J.; Blackstock, S. C.; Cha, J. K. J. Am. Chem. Soc. 1997, 119, 10241-10242. doi:10.1021/ja972115h

19. Ha, J. D.; Lee, J.; Blackstock, S. C.; Cha, J. K. J. Org. Chem. 1998, 63, 8510-8514. doi:10.1021/jo9817671

20. Blackburn, A.; Bowles, D. M.; Curran, T. T.; Kim, H. Synth. Commun. 2012, 42, 1855-1863. doi:10.1080/00397911.2010.545166

21. Prier, C. K.; Rankic, D. A.; MacMillan, D. W. C. Chem. Rev. 2013, 113, 5322-5363. doi:10.1021/cr300503r

22. Xi, Y.; Yi, H.; Lei, A. Org. Biomol. Chem. 2013, 11, 2387-2403. doi:10.1039/C3OB40137E

23. Xuan, J.; Xiao, W.-J. Angew. Chem., Int. Ed. 2012, 51, 6828-6838. doi:10.1002/anie.201200223

24. Tucker, J. W.; Stephenson, C. R. J. J. Org. Chem. 2012, 77, 1617-1622. doi:10.1021/jo202538x

25. Telpý, F. Collect. Czech. Chem. Commun. 2011, 76, 859-917. doi:10.1135/cccc2011078

26. Yoon, T. P.; Ischay, M. A.; Du, J. Nat. Chem. 2010, 2, 527-532. doi:10.1038/nchem.687

27. Shi, L.; Xia, W. Chem. Soc. Rev. 2012, 41, 7687-7697. doi:10.1039/C2CS35203F

28. Hu, J.; Wang, J.; Nguyen, T. H.; Zheng, N. Beilstein J. Org. Chem. 2013, 9, 1977-2001. doi:10.3762/bjoc.9.234

29. Maity, S.; Zhu, M.; Shinabery, R. S.; Zheng, N. Angew. Chem., Int. Ed. 2012, 51, 222-226. doi:10.1002/anie.201106162

30. Johannsen, M.; Jørgensen, K. A. Chem. Rev. 1998, 98, 1689-1708. doi:10.1021/cr970343o

31. Fischer, H.; Radom, L. Angew. Chem., Int. Ed. 2001, 40, 1340-1371. doi:10.1002/1521-3773(20010417)40:8<1340::AID-ANIE1340>3.0.CO; 2-\#

32. Giese, B.; Lachhein, S. Angew. Chem., Int. Ed. Engl. 1982, 21, 768-775. doi:10.1002/anie.198207681

33. Wille, U. Chem. Rev. 2013, 113, 813-853. doi:10.1021/cr100359d

34. Jiang, W.; Li, Y.; Wang, Z. Chem. Soc. Rev. 2013, 42, 6113-6127. doi:10.1039/C3CS60108K

35. Baumann, M.; Baxendale, I. R.; Ley, S. V.; Nikbin, N. Beilstein J. Org. Chem. 2011, 7, 442-495. doi:10.3762/bjoc.7.57

36. Baumann, M.; Baxendale, I. R. Beilstein J. Org. Chem. 2013, 9 , 2265-2319. doi:10.3762/bjoc.9.265

37. Liu, D.; Zhao, G.; Xiang, L. Eur. J. Org. Chem. 2010, 3975-3984. doi:10.1002/ejoc.201000323 
38. Xuan, J.; Lu, L.-Q.; Chen, J.-R.; Xiao, W.-J. Eur. J. Org. Chem. 2013, 6755-6770. doi:10.1002/ejoc.201300596

39. Surry, D. S.; Buchwald, S. L. Chem. Sci. 2011, 2, 27-50. doi:10.1039/C0SC00331J

40. Hartwig, J. F. Acc. Chem. Res. 2008, 41, 1534-1544. doi:10.1021/ar800098p

41. Littke, A. F.; Fu, G. C. J. Am. Chem. Soc. 2001, 123, 6989-7000. doi:10.1021/ja010988c

\section{License and Terms}

This is an Open Access article under the terms of the Creative Commons Attribution License

(http://creativecommons.org/licenses/by/2.0), which permits unrestricted use, distribution, and reproduction in any medium, provided the original work is properly cited.

The license is subject to the Beilstein Journal of Organic Chemistry terms and conditions:

(http://www.beilstein-journals.org/bjoc)

The definitive version of this article is the electronic one which can be found at: doi:10.3762/bjoc. 10.96 